\title{
OdOUR SENSOR BASEd SOLUTION For THE Sanitary Problem FaCed By Elderly People AND KINDERGARTEN CHILDREN
}

\author{
M.Karthick ${ }^{1}$, S.Sakthi Kannan ${ }^{2}$ and G.Velmathi ${ }^{3}$ \\ Department of Electronics and Communication Engineering \\ Velammal College of Engineering and Technology, Madurai - 625009
}

\begin{abstract}
Old age people and kindergarten children face health problems mainly due to deficiencies in sanitation. So a complete wireless health monitoring system which continuously monitors some of the vital body parameters such as body temperature, heart pulse rate, motion sensor and odour sensor can be designed. Our paper deals with the detection of ammonia (NH3) and hydrogen sulphide (H2S) using an odour sensor or a gas sensor.
\end{abstract}

\section{INTRODUCTION}

Improper urination and excretion leads too many problems which affect the human beings. This happens mainly to kindergarten children and old age people. It also affects the bed ridden people in hospitals. Because a normal human being use to urinate and excrete in a proper way so as to maintain his health. But an old aged people or a kindergarten child face a lot of problems during urination and excretion. They may not have any feel when they excrete or urinate which eventually leads to improper health conditions. These may cause many diseases as they have low immunity system to withstand diseases.

\section{PROPOSED MODEL}

Our proposed model can be used to eradicate this problem faced by old age people and kindergarten children. It consists of a sensor which is used to detect the presence of gases namely ammonia and hydrogen sulphide. These are the gases that are mainly released during urination and excretion. Hence the sensor is used to detect the presence of these gases from old age people and kindergarten children during these activities. As this is a daily activity, the sensors are also used to monitor them regularly for a better health. The main advantage of our model is that the sensor does a regular act in monitoring them from their daily activities. This avoids the care takers from monitoring them regularly during urination and excretion.

Another part is that the sensed gases can be transmitted to a particular place for regular monitoring of them. This makes their work rather easier for them. The sensed gases can be transformed into signals so that a wireless communication can be established between the monitoring place and old age people and kindergarten children. Hence a proper sanitation can be provided to them and their surroundings. Also their health conditions can be maintained in a better way which will increase their immune system.

The main backbone of our proposed model is the odour sensor. Henceforth it is discussed below.

DOI : $10.5121 /$ ijist.2014.4303 


\section{ODOUR SENSOR PURPOSE}

The purpose of odour sensor is to monitor the kindergarten children and old age people. Because when old age people are admitted in a general ward or a child is joined in a kindergarten, they have to be monitored mainly for their excreta and urinal problems. Many old age people lose their nerve senses in the genital region and children won't mind urinating without the presence of mind. As a result they will suffer from basic hygiene problems and it becomes a reason for the formation of diseases. These disease formations are caused due to poor sanitations.

Poor sanitation can be caused by contamination in food and water. The disease that comes due to such toilet insanitation includes cholera, dysentery, diarrhea, typhoid and stomach complications. This gas sensor or odour sensor has been exclusively designed for this purpose to prevent old age people and children getting affected from diseases. It is designed mainly foe sanitation.

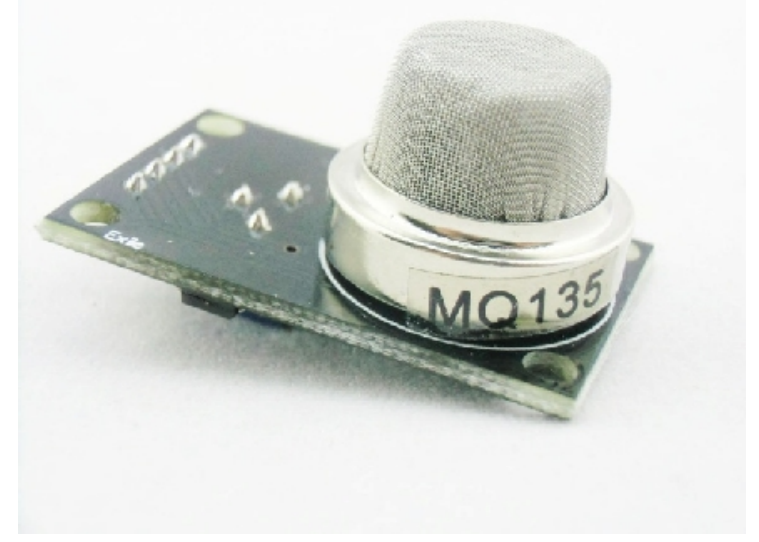

Figure.1 Odour sensor

It targets those gases and smell of wastes and shows the indication that the person has wastes in his clothes. This will solve the problem in advance thus preventing from diseases. When old age people and children are more in number, a wireless transmitter module can be used for remote monitoring.

\section{FACTORS TO SELECT ODOUR SENSOR}

\section{1) Selectivity}

The main challenge for developers is to have high selectivity of the metal-oxide gas sensors. There are two approaches generally for enhancing the sensors in selective properties. First one is specifically made sensitive to one compound and has low or zero cross-sensitivity to other compounds that are present in the atmosphere. Second approach is related to the preparation of materials for discrimination between several analytes in a mixture.

\section{2) Stability}

A metal-oxide gas sensor with low stability and long range signal drift leads to uncertain results, false alarms and the need to frequently recalibrate or replace the sensor. Stability can be increased by calcinations and annealing. Doping the metal-oxide with metal particles or carbon nanotubes as well as synthesis of mixed oxides increase the stability of sensor elements.

3) Sensitivity 
International Journal of Information Sciences and Techniques (IJIST) Vol.4, No.3, May 2014

This is the third factor to select a sensor element in detection of the target gases. If there is low sensitivity then it will lead to uncertain results. This can be increased by substantially dispersing a low concentration of additives such as $\mathrm{Pd}, \mathrm{Pt}, \mathrm{Au}, \mathrm{Ag}, \mathrm{Cu}, \mathrm{Co}$ and $\mathrm{F}$.

\section{METHOD FOR PRODUCING HYDROGEN SULPHIDE}

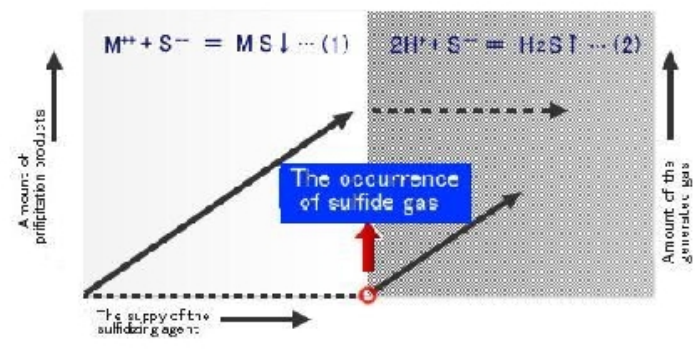

Figure.2 Hydrogen sulphide formation

We have verified that there is a relationship as shown in the diagram below between progress of formation of sulphide in the Solution containing metal ion and generating hydrogen sulphide gas. In case the sulphide is precipitated according to Formula (1) by adding sulphidizing agent to wastewater containing metal ion $(\mathrm{M}++)$, no Hydrogen sulphide generates in the reaction tank as long as metal ion remains even if $\mathrm{pH}$ is low. This is because reaction (1) precedes reaction (2). Hydrogen sulphide occurs after the density of metal ion becomes sufficiently low as the precipitate formation proceeds. Based on this fact, we have succeeded in inventing a method to control sulphide to be fed and thus to control precisely and stably the process of precipitation of sulphide.

NS Process features not only in its capacity Excellent Treatment of wastewater with heavy metals but Also in its wide applicable fields.

\section{METHOD FOR PRODUCING AMMONIA}

Ammonia gas is invisible as it moves through the air from Barry's opened bottle to Jennifer's nose. There is a simple demonstration that makes visible some consequences of this motion of ammonia. The demonstration uses what is called a diffusion chamber. This is a popular chemistry experiment in which two different gases, typically ammonia $\left(\mathrm{NH}_{3}\right)$ and hydrogen chloride $(\mathrm{HCl})$ diffuse from opposite ends of a closed glass tube (Figure 3). Eventually the two gases meet and react, forming a disk of white dust made of the solid ammonium chloride $\left(\mathrm{NH}_{4} \mathrm{Cl}\right)$. We say that the ammonium chloride is precipitated out of the gas.

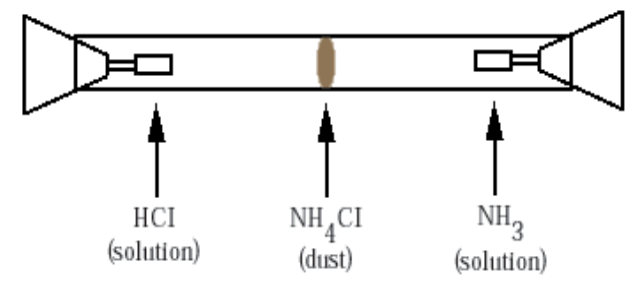

Figure.3 Diffusion Chamber Demonstration

The acid hydrogen chloride $\mathrm{HCl}$ (in water) is placed at one end, and evaporates as $\mathrm{HCl}$ gas. Ammonia, which is a water solution of ammonium hydroxide, is placed at the other end, and 
International Journal of Information Sciences and Techniques (IJIST) Vol.4, No.3, May 2014

gives off ammonia gas, $\mathrm{NH}_{3}$. The two gases diffuse down the tube where these gases first meet, they react chemically to make a disk-shaped cloud of dust composed of (the solid) ammonium chloride $\mathrm{NH}_{4} \mathrm{Cl}$.

\section{BLOCK DIAGRAM}

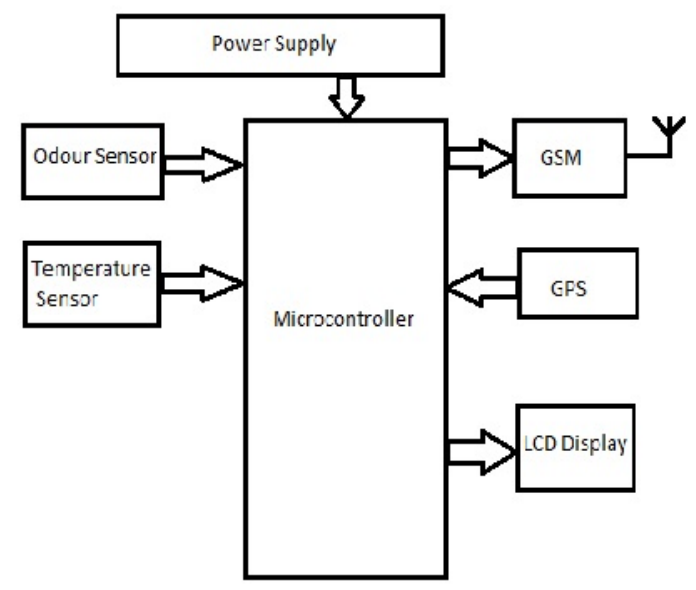

Figure.4 Block Diagram

\section{WORKING}

Sensitive material of MQ-135 gas sensor is $\mathrm{SnO}_{2}$, which has lower conductivity in clean air. The sensor's conductivity is more higher along with the as concentration rising. In clean air, the oxide layer acts as a barrier to prevail the low conductivity. When the target gas is passed namely ammonia (NH3) over the senor, hydrogen combines with oxygen and evaporates as water molecule. Hence the conductivity of the layer gets increased by decreasing the oxide layer. As a result the heater gets heated up and the target gas is detected.

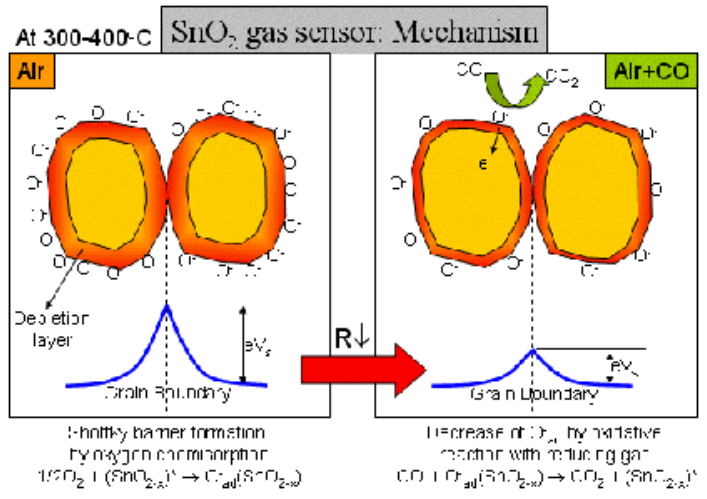

Figure.5 Mechanism of sensor

The input given is in analog form. As the microcontroller has an inbuilt ADC, it gets converted into digital form. This can be displayed using an LCD display. A set value is assumed such that when level of gas exceeds the value an alarm or beep can be given. 
International Journal of Information Sciences and Techniques (IJIST) Vol.4, No.3, May 2014

\section{HARDWARE SETUP}

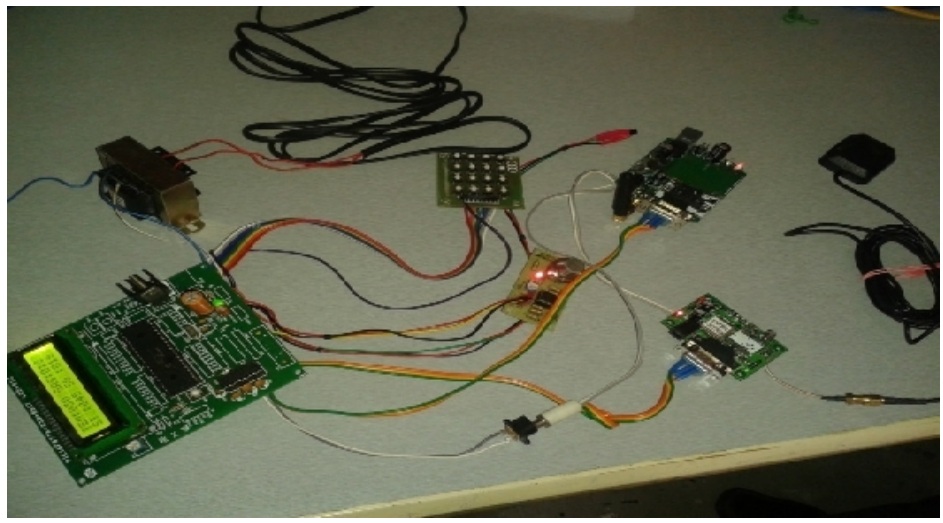

Figure.6 Hardware Setup

The hardware setup also consists of the GPS and GSM. The GPS receiver calculates the position by precisely timing the signals sent by GPS satellite high above the Earth. GSM is a cellular network, which means that cell phones are connected to it by searching the cells in immediate vicinity.

\section{RESULT}

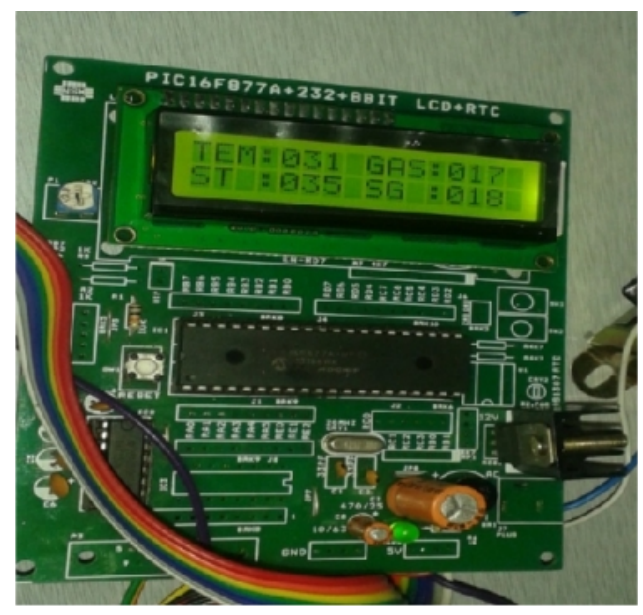

Figure.7 Temperature and Odour Sensssing

\section{CONCLUSION}

The circuit works fine, getting parameter envisaged during the conceptual stage. During the design of the circuit as well as construction, great care has been put to avoid hiccups at the final stage of the result. The PCB layouts were prepared with utmost care to incorporate the circuits in a modular manner. The circuit is simple to our knowledge. In future work, sensing of the film will be tested for higher response rate even at a very low concentration. The wireless range can also be increased up to kilometer in distance. 
International Journal of Information Sciences and Techniques (IJIST) Vol.4, No.3, May 2014

\section{ACKNOWLEDGEMENT}

The authors thank department of science and technology, instrument development program (DSTIDT) for financial support provided to this work.

\section{REFERENCES}

[1] Lorwongtragool, Baumann, Sowade, Watthanawisuth. A zigbee based wireless wearable electronic nose using flexible printed sensor array. Nano electronics Conference(INEC), 2013 IEEE 5th International

[2] Pogfay, T. ; Watthanawisuth, N. ; Wisitsoraat, A. ; Lomas, T.; Tuantranont, A. Industrial community odor monitoring utilizing wireless electronic nose for human health protection. Biomedical Engineering International Conference (BMEiCON), 2011

[3] Thepudom,T. Kerdcharoen, T.; Tuantranont, A. ; Pogfay, T.Health-care electronic nose to detect beer odor in breath after drinking. Biomedical Engineering International Conference (BMEiCON), 2012.

[4] Yusuf, N. ; Omar, M.I. ; Zakaria, A. ; Abdullah, A.A. ;Kamarudin, L.M. ; Shakaff, A.Y.M. ; Masnan, M.J. ;Zakaria, N.Z.I ; Yeap, E.J. ; Othman, A. ; Yassin, M.S.Diagnosis of bacteria for diabetic foot infection using electronic nose technology. Wireless Sensor (ICWISE), 2013 IEEE Conference.

[5] Huadong $\mathrm{Wu}$; Siegel, M. Odor-based incontinence sensor. Instrumentation and Measurement Tech. Conference

\section{Authors}

M.Karthick, Born in Madurai, India on $21^{\text {st }}$ of May 1993. The author is pursuing Bachelor degree in Velammal College of Engineering and Technology, Madurai, Tamil Nadu, India. His research interests are sensor networks and VLSI design.

S.Sakthi Kannan, Born in Madurai, India on $25^{\text {th }}$ of August 1992. The author is pursuing Bachelor degree in Velammal College of Engineering and Technology, Madurai, Tamil Nadu, India. His research interests are sensor networks and VLSI design.

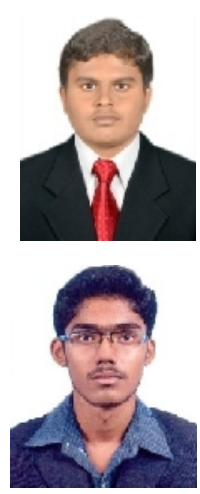

Dr.G.Velmathi is currently working as a professor in Electronics and Communication VCET and has teaching experience of 19 years. She has completed her B.E in Thiagarajar college of engineering and M.E in Madras Institute of Science and Technology. She Received her Ph.D from Indian Institute of Science as a full time research scholar and her are of interest is mainly RFMEMS, VLSI design and Biomedical instrumentation. She is the principal investigator of two ongoing DST projects worth 78Lakhs. She authored many paper works in the field of MEMS and VLSI.

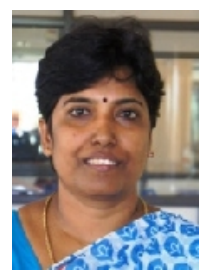

